\title{
Ice-sheet flow conditions deduced from mechanical tests of ice core
}

\author{
Atsushi Miyamoto, ${ }^{1}$ Hideki Narita, ${ }^{1}$ Takeo Hondoh, ${ }^{1}$ Hitoshi Shoji, ${ }^{2}$ Kunio Kawada, ${ }^{3}$ Okitsugu \\ Watanabe, ${ }^{4}$ Dorthe Dahl-jensen, ${ }^{5}$ Niels S. Gundestrup, ${ }^{5}$ Henrik B. Clausen, ${ }^{5}$ Paul Duval ${ }^{6}$ \\ ${ }^{1}$ Institute of Low Temperature Science, Hokkaido University, Sapporo, Hokkaido 060-0819, Japan \\ ${ }^{2}$ Kitami Institute of Technology, Kitami, Hokkaido 090-8507, Japan \\ ${ }^{3}$ Faculty of Science, Toyama University, Gofuku 3190, Toyama 930-8555, Japan \\ ${ }^{4}$ National Institute of Polar Research, Itabashi-ku, Tokyo 173-8515, Japan \\ ${ }^{5}$ The Niels Bohr Institute, Department of Geophysics, University of Copenhagen, DK-2200 Copenhagen, Denmark \\ ${ }^{6}$ Laboratoire de Glaciologie et Géophysique de l'Environnement du CNRS, BP 96, 38402 Saint-Martin-d'Hères Cedex, France
}

\begin{abstract}
Uniaxial compression tests were performed on samples of the Greenland Ice Core Project (GRIP) deep ice core, both in the field and later in a cold-room laboratory, in order to understand the ice-flow behavior of large ice sheets. Experiments were conducted under conditions of constant strain rate (type A) and constant load (type B). Fifty-four uniaxial-compression test specimens from 1327-2922 m were selected. Each test specimen $(25 \mathrm{~mm} \times 25 \mathrm{~mm} \times 90 \mathrm{~mm})$ was prepared with its uniaxial stress axis inclined $45^{\circ}$ from the core axis in order to examine the flow behavior of strong single-maximum ice-core samples with basal planes parallel to the horizontal plane of the ice sheet. The iceflow enhancement factors show a gradual increase with depth down to approximately $2000 \mathrm{~m}$. These results can be interpreted in terms of an increase in the fourth-order Schmid factor. Below $2000 \mathrm{~m}$ depth, the flow-enhancement factor increases to about 20 30 with a relatively high variability. When the Schmid factor was $>0.46$, the enhancement factor obtained was higher than expected from the $c$-axis concentrations measured. The higher values of flow-enhancement factor were obtained from specimens with a cloudy band structure. It was revealed that cloudy bands affect ice-deformation processes, but the details remain unclear.
\end{abstract}

\section{INTRODUCTION}

Ice-sheet flow conditions are strongly influenced by stress, temperature, crystal-orientation fabrics and the content of particular impurities, properties that generally vary with depth in large ice masses (Paterson, 1994). We need to understand the creep properties of polycrystalline ice in order to understand the ice-flow behavior of large ice sheets. Laboratory experiments have shown that the secondary creep rate of polycrystalline ice is as described by Glen (1955):

$$
\dot{\varepsilon}=B \sigma^{n} \exp \left(-\frac{Q}{\kappa T}\right), \quad n=3,
$$

where $B$ is a constant, $Q$ is the activation energy for creep of ice, $\kappa$ is Boltzmann's constant and $T$ is the absolute temperature. This relation, known as Glen's creep law for polycrystalline ice, does not, however, take into account the effect of crystal anisotropy. In natural ice masses, strong anisotropy exists. We have some knowledge of strain-rate dependence on fabric development in large ice masses (Shoji and Langway, 1988; Jacka and Budd, 1989).

A $3029 \mathrm{~m}$ long vertical ice core was recovered from Summit $\left(72^{\circ} 34.5^{\prime} \mathrm{N}, 37^{\circ} 38.5^{\prime} \mathrm{W}\right.$; $3230 \mathrm{~m}$ a.s.l.) during the boreal summers of 1990, 1991 and 1992 by the joint European research effort of the Greenland Ice Core Project (GRIP). The excellent physical condition of the deep ice core permits mechanical tests to be made of the flow properties over a wide range of sampling depths.
Stable-isotope measurements (Dansgaard and others, 1993; GRIP Project Members, 1993; Johnsen and others, 1995) clearly identify the Holocene ice (present-11.5 ka BP; top- $1624 \mathrm{~m})$, the Wisconsin ice (11.5-110 ka BP; 1624$2790 \mathrm{~m}$ ) and the Sangamon ice (110-135 ka BP; 2790$2865 \mathrm{~m}$ ) along the GRIP ice core. The bottom parts of the core show largely disturbed visual stratigraphy (2850$2950 \mathrm{~m}$ ), which raises questions regarding chronological continuity at those depths (Thorsteinsson and others, 1997).

The general physical features of the entire GRIP ice core have been studied by Thorsteinsson and others (1997), and flow disturbance of the GRIP and Greenland Ice Sheet Project II (GISP2) deep ice cores has been reported by Alley and others (1995). Other studies having a bearing on our measurements include chemical and dust measurements (personal communication from J. P. Steffensen and others, 1997; personal communication from C. U. Hammer and others, 1997) and electric conductivity measurements (ECMs) in the field (personal communication from H. B. Clausen and others, 1997).

\section{SAMPLES, TEST SPEGIMENS AND EXPERIMENTS}

Uniaxial compression tests were made on the GRIP deep icecore samples in the field and laboratory. Experiments were conducted under conditions of constant strain rate (type A) and constant load (type B). Thirty-nine core samples (approximately $35 \mathrm{~mm} \times 100 \mathrm{~mm} \times 550 \mathrm{~mm}$ ) were selected from 
777-2922 m over the vertical core profile, excluding the volcanic impurity layers detected by ECMs (personal communication from H. B. Clausen and others, 1992). Brittle-zone (650-1300 m) samples were not included for the compression tests. The depth of each test sample is marked on the stableisotope profile (Dansgaard and others, 1993) in Figure 1. Grain-size (Thorsteinsson and others, 1995) is nearly constant (2-3 mm) in Holocene ice below $700 \mathrm{~m}$ depth, but decreases to $1-2 \mathrm{~mm}$ below the Holocene/Wisconsin boundary depth. Below $2000 \mathrm{~m}$ depth, grain-size increases with depth towards the bottom, with large fluctuations $(4-13 \mathrm{~mm})$. The uniaxial compression tests were made on samples selected from identified climate periods (Holocene, Wisconsin and Sangamon) in the GRIP core, providing a wide variation in grain-size, fabrics and impurity content. Test specimens (approximately $25 \mathrm{~mm} \times 25 \mathrm{~mm} \times 90 \mathrm{~mm}$ ) were prepared from core samples with the uniaxial-stress axis inclined $45^{\circ}$ from the core axis in order to examine the relation between the single-maximum $c$-axis orientation and the basal plane easy-slip system in the direction of the horizontal plane of the ice sheet. The stress field of the GRIP site is understood to be uniaxial compression, but, in order to understand anisotropy in ice-sheet flow, we chose the sample-cutting plan outlined above. Furthermore, Castelnau and others (1998) show that the flow results from compression tests are very sensitive to slight deviations between the compression axis and the core axis when the stress is applied in the direction of the core axis (in situ stress field at the dome). When uniaxial compression tests are performed inclined at $45^{\circ}$ from the core axis, experiments provide a good measurement of the directional viscosity corresponding to an in situ horizontal shear (Castelnau and others, 1998). A constant strain rate of about $4.5 \times 10^{-8} \mathrm{~s}^{-1}$ was applied for the type A experiments with a Minebea Model TCM-5knb-S testing instrument which was specially modified for low-speed testing. A constant stress in the range 0.2$0.7 \mathrm{MPa}$ was applied for the type B experiments with a specially designed creep-testing apparatus made at Toyama University. The strain rate for our laboratory test is very high

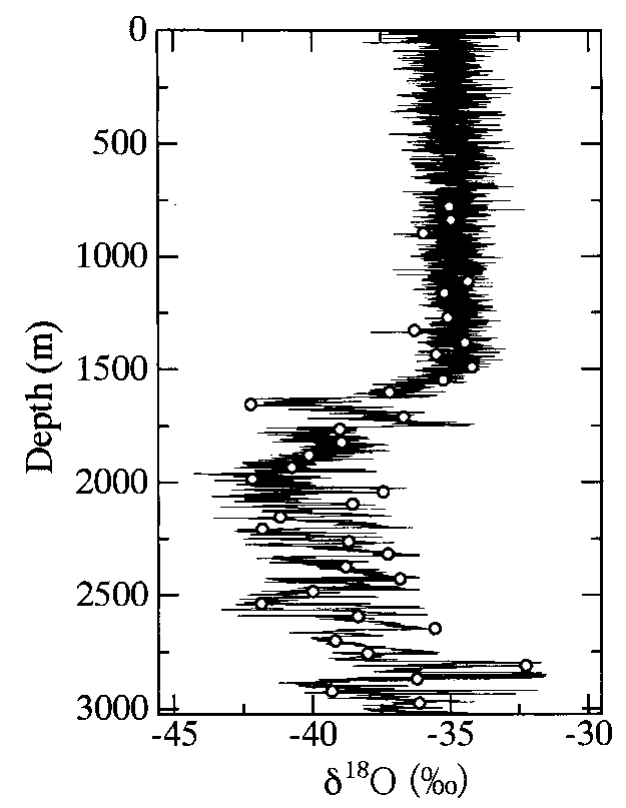

Fig. 1. Stable-isotope curve for the GRIP ice core (Dansgaard and others, 1993). Slab-section samples for this study are shown by open circles. compared with the ice-sheet flow. We need to perform various deformation tests to examine whether laboratory tests can be adapted to ice-sheet flow, and to establish a flow law for anisotropic ice in the ice sheet. The experimental temperature ranged from $-11^{\circ}$ to $-17^{\circ} \mathrm{C}$, and was held constant during each test run, as shown in Table 1 .

Table 1. Conditions and results of uniaxial compression tests

\begin{tabular}{|c|c|c|c|c|c|c|c|c|c|}
\hline \multirow[t]{2}{*}{$\begin{array}{c}\text { Bag } \\
\text { No. }\end{array}$} & \multirow{2}{*}{$\begin{array}{l}\text { Specimen } \\
\text { No. and } \\
\text { test type }\end{array}$} & \multirow{2}{*}{$\begin{array}{c}\text { Depth } \\
\text { m }\end{array}$} & \multirow[t]{2}{*}{$\begin{array}{l}\text { Schmid } \\
\text { factor }\end{array}$} & \multirow{2}{*}{$\begin{array}{l}\text { Stress } \\
\mathrm{MPa}\end{array}$} & \multirow{2}{*}{$\begin{array}{c}\text { Strain } \\
\text { rate } \\
10^{-8} \mathrm{~s}^{-1}\end{array}$} & \multirow{2}{*}{$\begin{array}{c}\text { Total } \\
\text { strain } \\
\%\end{array}$} & \multirow{2}{*}{$\begin{array}{l}\text { Temp. } \\
{ }^{\circ} \mathrm{C}\end{array}$} & \multirow{2}{*}{$\begin{array}{l}B \\
*\end{array}$} & \multirow[t]{2}{*}{ Remarks } \\
\hline & & & & & & & & & \\
\hline 2414 & $1 \mathrm{~A}$ & 1327 & 0.406 & 0.64 & 4.5 & 1.3 & -11.2 & 1.6 & Field data \\
\hline 2414 & $1 \mathrm{~B}$ & 1327 & 0.406 & 0.51 & 1.6 & 2.1 & -15.0 & 1.7 & \\
\hline 2514 & $2 \mathrm{~A}$ & 1382 & 0.359 & 0.75 & 4.5 & 1.7 & -15.0 & 1.4 & \\
\hline 2514 & $2 \mathrm{~B}$ & 1382 & 0.359 & 0.68 & 4.5 & 2.8 & -15.0 & 1.9 & \\
\hline 2614 & $3 \mathrm{~A}$ & 1437 & 0.378 & 0.61 & 4.5 & 1.4 & -11.2 & 1.8 & Field data \\
\hline 2614 & $3 B$ & 1437 & 0.378 & 0.58 & 1.6 & 1.2 & -15.0 & 1.2 & \\
\hline 2714 & $4 \mathrm{~A}$ & 1492 & 0.391 & 0.81 & 4.6 & 3.0 & -15.0 & 1.2 & \\
\hline 2714 & $4 \mathrm{~B}$ & 1492 & 0.391 & 0.68 & 3.2 & 2.4 & -15.0 & 1.4 & \\
\hline 2815 & $5 \mathrm{~A}$ & 1548 & 0.405 & 0.65 & 4.5 & 1.6 & -12.0 & 1.6 & Field data \\
\hline 2815 & $5 B$ & 1548 & 0.405 & 0.64 & 1.8 & 1.5 & -15.0 & 1.0 & \\
\hline 2914 & $6 \mathrm{~A}$ & 1602 & 0.405 & 0.56 & 4.4 & 5.5 & -15.0 & 3.6 & \\
\hline 2914 & $6 \mathrm{~B}$ & 1602 & 0.405 & 0.51 & 2.0 & 1.4 & -15.0 & 2.1 & \\
\hline 3014 & $7 \mathrm{~A}$ & 1657 & 0.423 & 0.51 & 4.6 & 2.4 & -11.7 & 3.3 & Field data \\
\hline 3014 & $7 \mathrm{~B}$ & 1657 & 0.423 & 0.69 & 6.7 & 3.5 & -15.0 & 2.8 & \\
\hline 3114 & $8 \mathrm{~A}$ & 1712 & 0.424 & 0.58 & 4.5 & 3.0 & -15.0 & 3.2 & \\
\hline 3114 & $8 B$ & 1712 & 0.424 & 0.62 & 3.2 & 2.6 & -15.0 & 1.9 & \\
\hline 3214 & $9 \mathrm{~A}$ & 1767 & 0.454 & 0.67 & 4.5 & 3.4 & -15.0 & 2.1 & \\
\hline 3214 & $9 \mathrm{~B}$ & 1767 & 0.454 & 0.46 & 1.3 & 14.8 & -15.0 & 1.8 & \\
\hline 3315 & $10 \mathrm{~A}$ & 1823 & 0.448 & 0.40 & 4.6 & 4.7 & -15.0 & 10.2 & \\
\hline 3315 & $10 \mathrm{~B}$ & 1823 & 0.448 & 0.50 & 2.2 & 1.3 & -15.0 & 2.5 & \\
\hline 3415 & $11 \mathrm{~A}$ & 1878 & 0.45 & 0.61 & 4.5 & 5.2 & -15.0 & 2.7 & \\
\hline 3415 & $11 \mathrm{~B}$ & 1878 & 0.45 & 0.50 & 2.2 & 19.2 & -15.0 & 2.4 & \\
\hline 3514 & $12 \mathrm{~A}$ & 1932 & 0.458 & 0.55 & 4.5 & 3.1 & -15.0 & 3.8 & \\
\hline 3514 & $12 \mathrm{~B}$ & 1932 & 0.458 & 0.51 & 3.4 & 2.0 & -15.0 & 3.5 & \\
\hline 3614 & $13 \mathrm{~A}$ & 1987 & 0.452 & 0.47 & 4.6 & 1.7 & -15.0 & 5.9 & \\
\hline 3614 & $13 \mathrm{~B}$ & 1987 & 0.452 & 0.53 & 3.9 & 3.7 & -15.0 & 3.6 & \\
\hline 3714 & $14 \mathrm{~A}$ & 2042 & 0.454 & 0.39 & 4.3 & 3.7 & -15.0 & 10.3 & \\
\hline 3714 & $14 \mathrm{~B}$ & 2042 & 0.454 & 0.54 & 5.5 & 5.4 & -15.0 & 4.9 & \\
\hline 3814 & $15 \mathrm{~A}$ & 2097 & 0.467 & 0.52 & 4.5 & 4.5 & -15.0 & 4.4 & $\mathrm{E}$ \\
\hline 3814 & $15 \mathrm{~B}$ & 2097 & 0.467 & 0.51 & 7.1 & 3.9 & -15.0 & 7.2 & $\mathrm{E}$ \\
\hline 3915 & $16 \mathrm{~A}$ & 2153 & 0.476 & 0.33 & 4.6 & 2.2 & -15.0 & 17.0 & \\
\hline 3915 & $16 \mathrm{~B}$ & 2153 & 0.476 & 0.35 & 2.8 & 2.2 & -15.0 & 9.3 & \\
\hline 4014 & $17 \mathrm{~A}$ & 2207 & 0.478 & 0.34 & 4.6 & 4.5 & -15.0 & 15.8 & $\mathrm{E}$ \\
\hline 4014 & $17 \mathrm{~B}$ & 2207 & 0.478 & 0.35 & 3.9 & 3.0 & -15.0 & 13.2 & $\mathrm{E}$ \\
\hline 4114 & $18 \mathrm{~A}$ & 2262 & 0.465 & 0.26 & 4.5 & 2.5 & -15.0 & 36.5 & \\
\hline 4214 & $19 \mathrm{~A}$ & 2317 & 0.474 & 0.24 & 4.4 & 1.4 & -15.0 & 43.3 & \\
\hline 4318 & $18 B$ & 2375 & 0.483 & 0.33 & 6.3 & 5.1 & -15.0 & 23.8 & \\
\hline 4318 & $20 \mathrm{~A}$ & 2375 & 0.483 & 0.25 & 4.4 & 4.6 & -15.0 & 40.0 & \\
\hline 4414 & 19B & 2427 & 0.491 & 0.36 & 6.9 & 4.9 & -15.0 & 20.8 & \\
\hline 4414 & $21 \mathrm{~A}$ & 2427 & 0.491 & 0.26 & 4.5 & 2.5 & -15.0 & 36.7 & \\
\hline 4515 & $20 \mathrm{~B}$ & 2483 & 0.489 & 0.24 & 5.5 & 5.2 & -15.0 & 54.9 & \\
\hline 4613 & $21 \mathrm{~B}$ & 2537 & 0.495 & 0.24 & 6.4 & 6.1 & -15.0 & 65.1 & $\mathrm{D}$ \\
\hline 4715 & $22 \mathrm{~A}$ & 2593 & 0.490 & 0.26 & 4.4 & 4.7 & -15.0 & 34.3 & $\mathrm{D}$ \\
\hline 4715 & $22 \mathrm{~B}$ & 2593 & 0.490 & 0.21 & 2.6 & 1.8 & -15.0 & 37.5 & $\mathrm{D}$ \\
\hline 4814 & $23 \mathrm{~B}$ & 2647 & 0.477 & 0.31 & 6.1 & 7.8 & -15.0 & 29.6 & $\mathrm{D}$ \\
\hline 4914 & $23 \mathrm{~A}$ & 2702 & 0.495 & 0.25 & 4.7 & 6.5 & -15.0 & 42.5 & $\mathrm{E}$ \\
\hline 4914 & $24 \mathrm{~B}$ & 2702 & 0.495 & 0.36 & 7.9 & 5.5 & -15.0 & 23.0 & $\mathrm{E}$ \\
\hline 5014 & $24 \mathrm{~A}$ & 2757 & 0.451 & 0.34 & 4.5 & 4.2 & -15.0 & 15.9 & $\mathrm{E}$ \\
\hline 5014 & $25 \mathrm{~B}$ & 2757 & 0.451 & 0.43 & 4.4 & 10.0 & -15.0 & 7.8 & $\mathrm{E}$ \\
\hline 5114 & $25 \mathrm{~A}$ & 2812 & 0.430 & 0.20 & 4.5 & 5.2 & -15.0 & 81.9 & $\mathrm{E}$ \\
\hline 5214 & $26 \mathrm{~A}$ & 2867 & 0.481 & 0.28 & 4.0 & 1.9 & -15.0 & 26.2 & $\mathrm{E}, \mathrm{D}$ \\
\hline 5214 & $26 \mathrm{~B}$ & 2867 & 0.481 & 0.36 & 8.2 & 5.1 & -15.0 & 25.4 & E, D \\
\hline 5314 & $27 \mathrm{~A}$ & 2922 & 0.393 & 0.66 & 4.6 & 4.3 & -15.0 & 2.2 & E, D \\
\hline 5314 & $27 \mathrm{~B}$ & 2922 & 0.393 & 0.44 & 1.5 & 8.4 & -15.0 & 2.4 & $\mathrm{E}, \mathrm{D}$ \\
\hline
\end{tabular}

* in $10^{5} \mathrm{~s}^{-1} \mathrm{MPa}^{-3}$

Note: In the remarks column, $\mathrm{E}$ indicates layer disturbance in electrical conductivity; D indicates layer disturbance in visual stratigraphy. 


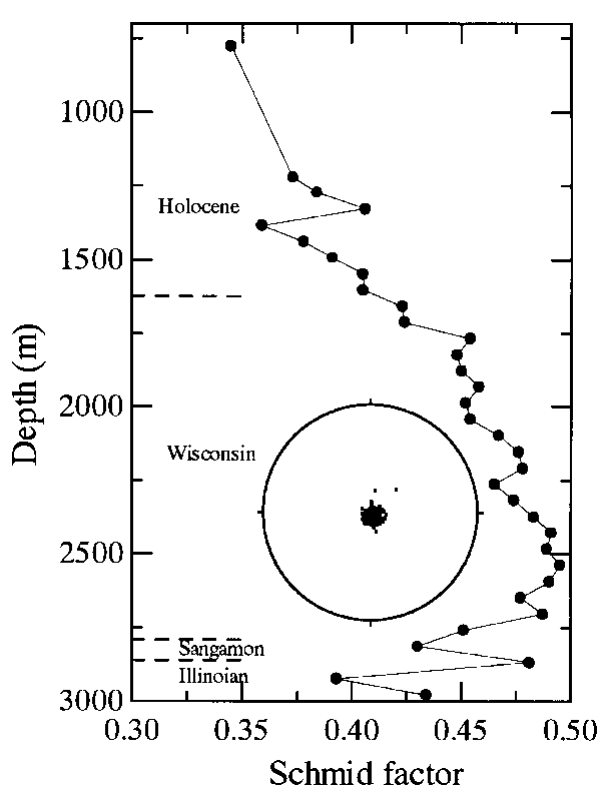

Fig. 2. Schmid-factor profile calculated from c-axis orientation studies. The fabric diagram showes the strongest singlemaximum c-axis orientation at $2537 \mathrm{~m}$ depth in the GRIP ice core.

\section{c-AXIS ORIENTATION DISTRIBUTION}

The influence of $c$-axis orientation on ice-flow behavior is well recognized. The effects can be described in terms of a Schmid factor (Shoji and Langway, 1988; Shoji and others, 1992; Azuma, 1995). The general distribution of $c$-axis orientation in the GRIP ice core has been measured by Thor-
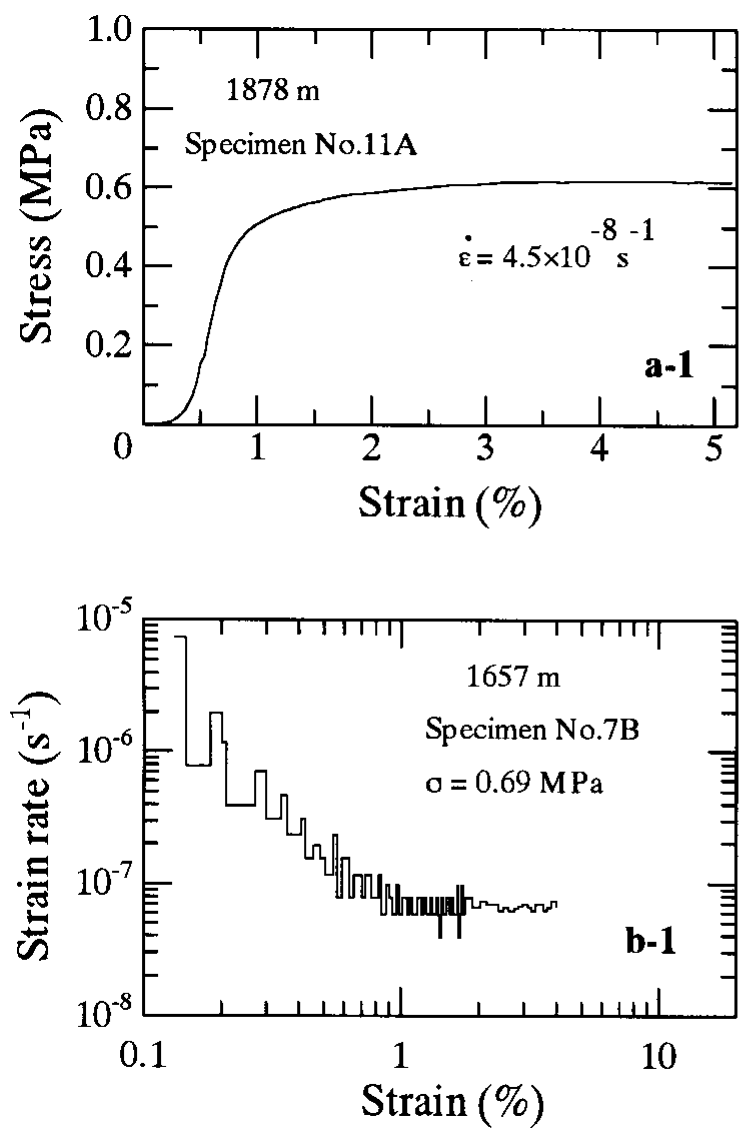

steinsson and others (1997). The average values of Schmid factor, $S$, with respect to the stress direction were calculated from $c$-axis measurements on the same ice-core section from which test samples were cut. The Schmid factor is defined as

$$
S=\left(\frac{\sum \sin \theta \cos \theta}{\mathcal{N}}\right),
$$

where $\theta$ is the angle between the $c$-axis direction of individual crystals and the stress-axis direction and $N$ is the number of crystals. The Schmid factor (Fig. 2) generally increases with depth down to about $2500 \mathrm{~m}$, with relatively small variability. Below $2500 \mathrm{~m}$ the Schmid factor appears to decrease rapidly with depth, with large perturbations. The major Holocene/ Wisconsin climate boundary identified at $1624 \mathrm{~m}$ by $\delta^{18} \mathrm{O}$ and ECM signals does not appear to be reflected in these data. The inclination of borehole is within $2^{\circ}$ from surface to $2300 \mathrm{~m}$ depth. Subsequently, the inclination reached $3^{\circ}$ at $3000 \mathrm{~m}$ depth (Johnsen and others, 1994). This inclination scarcely influences the Schmid factor.

\section{UNIAXIAL GOMPRESSION TESTS}

A total of 54 uniaxial compression tests were conducted as shown in Table 1. The stress-strain curves obtained from type A experiments were of a stress-saturation type in which stress levels remained approximately constant after $1 \%$ strain. The maximum value of the uniaxial stress was used in the data analysis that follows. The creep curves obtained from the type $\mathrm{B}$ experiments showed an almost constant minimum strain rate after about $1 \%$ strain which was also used for the following data analysis. Figures $3 \mathrm{a}$ (1 and 2) and b (1 and 2) show type $\mathrm{A}$ and type $\mathrm{B}$ data, respectively.
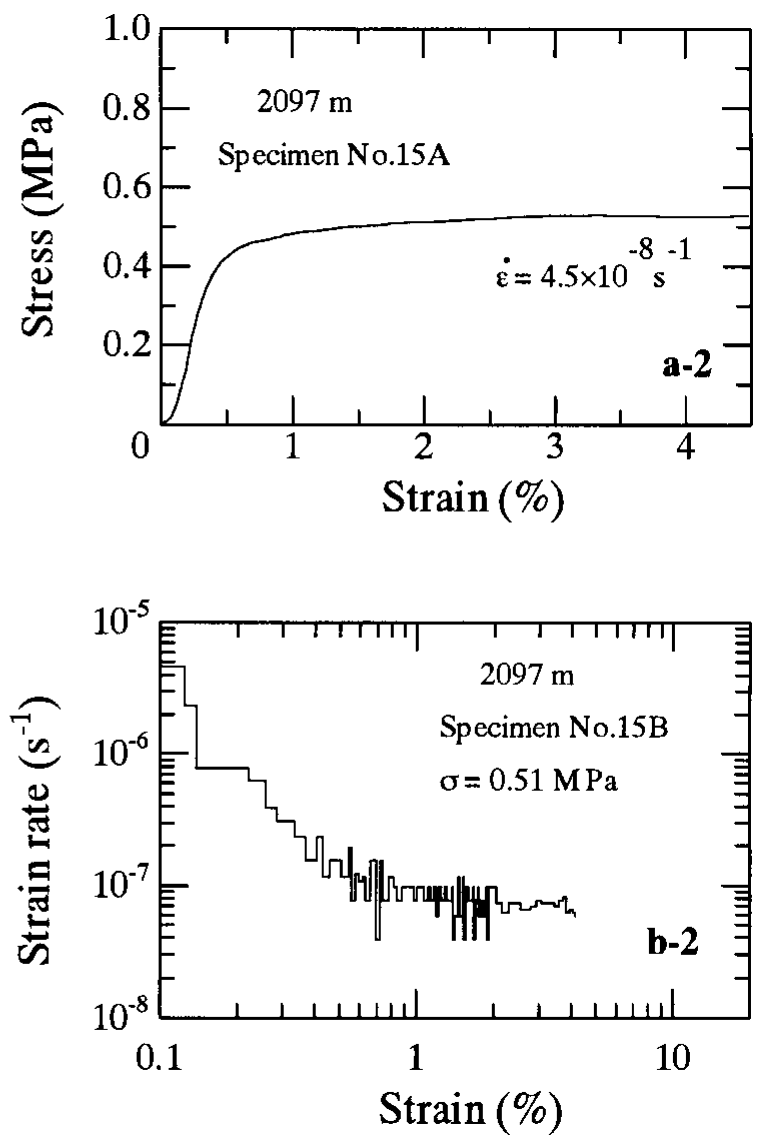

Fig. 3. Uniaxial-compression test curves. ( $a-1, a-2)$ Stress-strain relation, obtained from type A tests. (b-1, b-2) Strain-ratestrain relation, obtained from the type $B$ tests. 


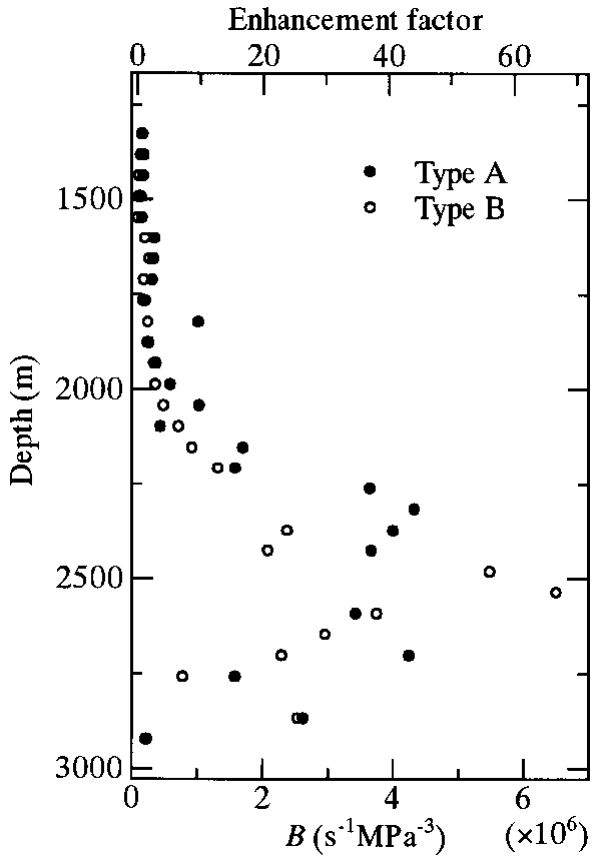

Fig. 4. B curve obtained from uniaxial compression tests. The top axis shows the flow-enhancement factor.

In Equation (1), B depends on crystal orientation (Schmid factor), impurity content, grain-size, grain shape and other factors apart from temperature. We used $60 \mathrm{~kJ} \mathrm{~mol}^{-1}$ for the activation energy $Q$ in our test temperature range (Weertman, 1983). The value of $B$ indicates the relative strain rate for a given stress and temperature. Values of $B$ (Fig. 4) show a very gradual increase from $777 \mathrm{~m}$ depth to $2200 \mathrm{~m}$ depth, with no significant difference in the increasing trend between results from type A and type B experiments. Below $2200 \mathrm{~m}$ depth, the values of $B$ increase markedly and show large scatter.

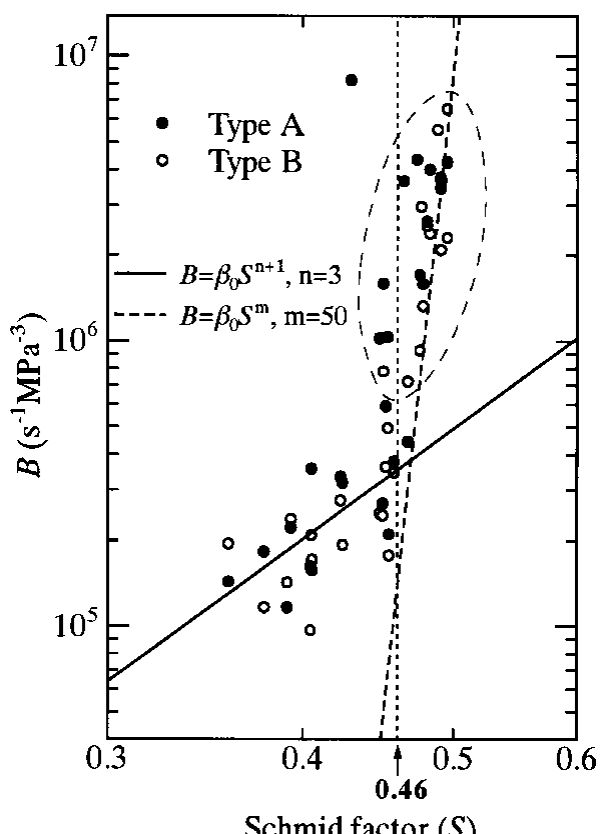

Fig. 5. Correlation of the value of $B$ with Schmid factors. The filled circles and open circles represent data from type $A$ and type B compression tests, respectively. The solid line is the regression line for $S<0.46$. The dashed line shows the 50thorder Schmid factor plotted against $B$.

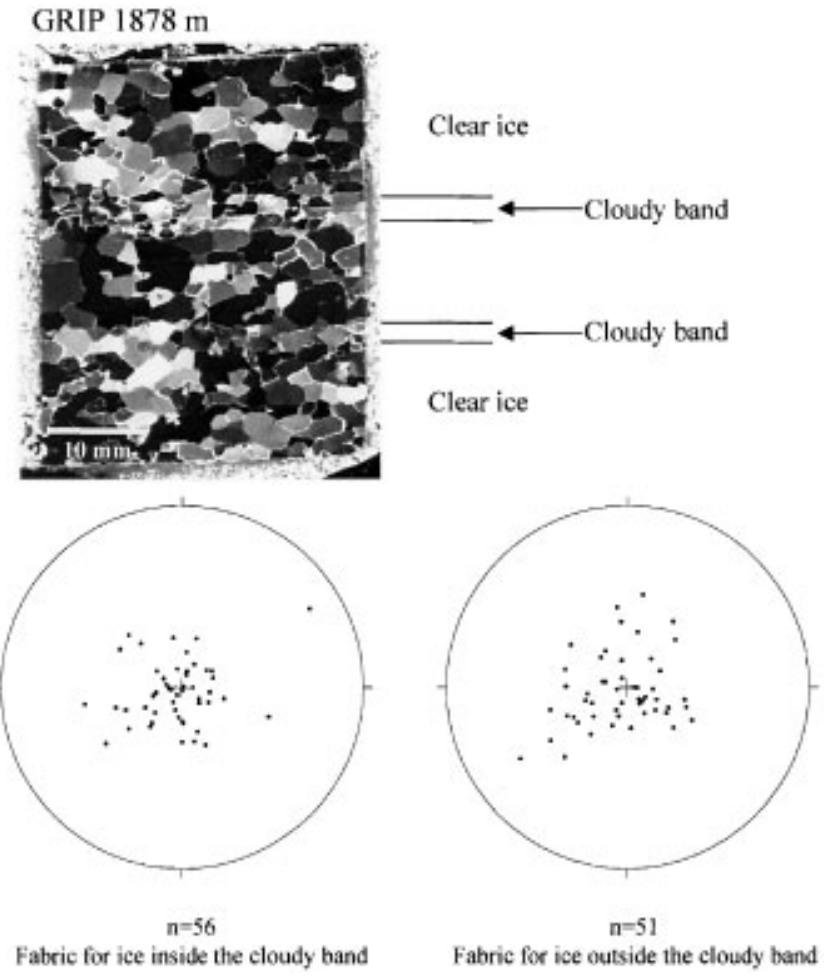

Fig. 6. Photograph through crossed polarizers of a vertical thin section, showing the typical cloudy-band structure in the GRIP ice-core sample from $1878 \mathrm{~m}$ depth. The Schmidt-net plots represent c-axis orientation for ice inside and outside the cloudy band.

\section{DISGUSSION AND GONGLUSIONS}

In order to obtain the relation between Schmid factor and strain rate, Equation (1) is redescribed as

$$
\dot{\varepsilon}=\beta_{0} S^{n+1} \sigma^{n} \exp \left(-\frac{Q}{\kappa T}\right), \quad n=3,
$$

where $\beta_{0}$ which it is supposed depends on impurity content, grain-size, grain shape and other factors is assumed to be constant and $S$ is the Schmid factor (Azuma, 1995). We can extract ice which exhibits strong single-maximum fabrics with a large $(>0.46)$ Schmid factor from the deeper part of the GRIP ice core (Fig. 2). Figure 5 shows a $\log -\log$ plot of the relation between $B$ and the Schmid factor, and from it we conclude that $B$ is proportional to $S^{4}$ for $S<0.46$. In this area, we see that Equation (3) is satisfied. For $S>0.46$, however, the values of $B$ have a wide spread for almost the same value of $S$. Alternatively the values of $B$ are proportional to about $S^{50}$.

In Figure 5, for a random $c$-axis orientation distribution ( $S=1 / 3), B=B_{1 / 3}$ is $9.7 \times 10^{4} \mathrm{~s}^{-1} \mathrm{MPa}^{-3}$ by extrapolation of the solid line. The ratio of $B$ to $B_{1 / 3}$ indicates the flow-enhancement factor $(E)$. The value of $E$ calculated on this basis is marked on the top axis in Figure 4. Low $E$ values persist right through the Holocene/Wisconsin boundary at $1624 \mathrm{~m}$, without change. This observed trend is quite different from that reported for the Dye 3 case (Shoji and Langway, 1987). This result suggests that the rate of development of the $c$-axis orientation fabric does not change drastically at the Holocene/Wisconsin boundary. Below around $2000 \mathrm{~m}$ depth, the value of $E$ indicates a factor of 2-3 difference between type A and type B experiments with very high values of $E(>20)$. Dahl-Jensen and others (1997) showed that deformation tests 
in the stress direction parallel to the core axis on the GRIP ice core indicate a vertical uniaxial compression strain-rate difference of 2-3 between the cold-period and warm-period ice. These deformational differences in the anisotropic distributions appear to be due to differences of $c$-axis orientation, grain-size, grain shape and impurity content.

The dataset enclosed by the dashed ellipse in Figure 5 consists of ice containing cloudy bands and layer disturbance in electrical conductivity and/or visual stratigraphy (Table 1). For the ECMs, eight scans were made with electrodes $10 \mathrm{~mm}$ apart. Slab-section samples were $0.1 \mathrm{~m}$ wide, and we can measure the layer structure at a scale of a few $\mathrm{cm}$. The cloudy bands are alternating layers of milky-colored, cloudy ice and clear ice, with dimensions of a few $\mathrm{mm}$ to a few $\mathrm{cm}$. The cloudy bands are identified as low- $\delta^{18} \mathrm{O}$ ice with small grain-size (Fig. 6) and low electrical conductivity. Similar bands are associated with a strong $c$-axis orientation in the Byrd ice core, Antarctica (Gow and Williamson, 1976). We obtain the opposite result in the GRIP ice core (Fig. 6): the $c$ axes in the clear ice tend to be more tightly concentrated than those in the cloudy band in the GRIP ice core. Miyamoto and others (1997) suggested that there is no clear correlation between the deformation rate and the number of cloudy bands in uniaxial-compression test specimens. However, it is expected that this anisotropic ice could deform differently than the almost isotropic ice of the Holocene period. Using a microscope, non-uniform deformation was observed at the scale of the cloudy-band structure in the Wisconsin ice, and the deformation mechanism is expected to be different in the cloudy-band ice than in clear ice. For treatments of the flow behavior of Antarctic and Greenland ice masses, quantitative understanding of the deformation properties of laminar-type, non-uniform ice is required.

\section{ACKNOWLEDGEMENTS}

The authors would like to thank all members of the Greenland Ice Core Project, organized by the European Science Foundation, for their support and cooperation in this study. We also thank the National Science Foundations of Denmark and France, and the Japanese Ministry of Education for financial support. Discussions with T. H. Jacka were helpful and his suggestions have improved this paper.

\section{REFERENCES}

Alley, R. B., A. J. Gow, S. J. Johnsen, J. Kipfstuhl, D. A. Meese and Th. Thorsteinsson. 1995. Comparison of deep ice cores. Nature, 373(6513), 393-394.

Azuma, N. 1995. A flow law for anisotropic polycrystalline ice under uniaxial compressive deformation. Cold Reg. Sci. Technol., 23(2), 137-147.

Castelnau, O. and 7 others. 1998. Anisotropic behavior of GRIP ices and flow in central Greenland. Earth Planet. Sci. Lett., 154(1-4), 307-322.

Dahl-Jensen, D., Th. Thorsteinsson, R. Alley and H. Shoji. 1997. Flow properties of the ice from the Greenland Ice Core Project ice core: the reason for folds? F. Geophys. Res., 102 (C12), 26,831-26,840.

Dansgaard, W. and 10 others. 1993. Evidence for general instability of past climate from a 250-kyr ice-core record. Nature, 364(6434), 218-220..

Glen, J.W. 1955. The creep of polycrystalline ice. Proc. R. Soc. London, Ser. A, 228(1175), 519-538.

Gow, A. J. and T. Williamson. 1976. Rheological implications of the internal structure and crystal fabrics of the West Antarctic ice sheet as revealed by deep core drilling at Byrd Station. CRREL Rep. 76-35.

GRIP Project Members. 1993. Climatic instability during the last interglacial revealed in the Greenland Summit ice-core. Nature, 364(6434), 203-207.

Jacka, T. H. and W.F. Budd. 1989. Isotropic and anisotropic flow relations for ice dynamics. Ann. Glaciol., 12, 81-84.

Johnsen, S. J., N. S. Gundestrup, S. B. Hansen, J. Schwander and H. Rufli. 1994. The new improved version of the ISTUK ice core drill. Natl. Inst. Polar Res. Mem., Special Issue 49, 9-23.

Johnsen, S. J., H. B. Clausen, W. Dansgaard, N. S. Gundestrup, C. U. Hammer and H. Tauber. 1995. The Eem stable isotope record along the GRIP ice core and its interpretation. Quat. Res., 43(2), 117-124.

Miyamoto, A., H. Shoji, H. Narita, O. Watanabe, H. B. Clausen and T. Hondoh. 1997. An attempt at deformation tests of deep ice core samples containing cloudy bands. Proc. NIPR Symp. Polar Meteorol. Glaciol. 11, 87-93.

Paterson, W. S. B. 1994. The physics of glaciers. Third edition. Oxford, etc., Elsevier.

Shoji, H. and C. C. Langway, Jr. 1987. Flow velocity profiles and accumulation rates from mechanical tests on ice core samples. International Association of Hydrological Sciences Publication 170 (Symposium at Vancouver 1987 - The Physical Basis of Ice Sheet Modelling), 67-77.

Shoji, H. and C. C. Langway, Jr. 1988. Flow-law parameters of the Dye 3, Greenland, deep ice core. Ann. Glaciol., 10, 146-150.

Shoji, H., M. Kobayashi and C. C. Langway, Jr. 1992. Crystal orientation fabrics affecting flow behaviors of polycrystalline ice. In Maeno, N. and T. Hondoh, eds. Proceedings of the International Symposium on the Physics and Chemistry of Ice, Sapporo, Japan. Hokkaido, Hokkaido University Press, 406-407.

Thorsteinsson, Th., J. Kipfstuhl, H. Eicken, S. J. Johnsen and K. Fuhrer. 1995. Crystal size variations in Eemian-age ice from the GRIP ice core, central Greenland. Earth Planet. Sci. Lett., 131 (3-4), 381-394.

Thorsteinsson, Th., J. Kipfstuhl and H. Miller. 1997. Textures and fabrics in the GRIP ice core. F. Geophys. Res., 102(C12), 26,583-26,600.

Weertman, J. 1983. Creep deformation of ice. Annu. Rev. Earth Planet. Sci., 11, 215-240. 